\title{
Challenges in the culture-independent analysis of oral and respiratory samples from intubated patients
}

\section{Vladimir Lazarevic ${ }^{1 *}$, Nadia Gaïa ${ }^{1}$, Stéphane Emonet ${ }^{2,3}$, Myriam Girard $^{1}$, Gesuele Renzi ${ }^{2}$, Lena Despres ${ }^{2}$, Hannah Wozniak ${ }^{2}$, Javier Yugueros Marcos ${ }^{4}$, Jean-Baptiste Veyrieras ${ }^{5}$, Sonia Chatellier ${ }^{6}$, Alex van Belkum ${ }^{6}$, Jérôme Pugin ${ }^{7}$ and Jacques Schrenzel ${ }^{1,2}$}

\author{
Genomic Research Laboratory, Department of Genetics and Laboratory Medicine and Department of Medical Specialties, Geneva University Hospitals, Geneva, \\ Switzerland \\ ${ }^{2}$ Clinical Microbiology Laboratory, Department of Genetics and Laboratory Medicine and Department of Medical Specialties, Geneva University Hospitals, Geneva, \\ Switzerland \\ ${ }^{3}$ Department of Internal Medicine, Rehabilitation and Geriatrics, Geneva University Hospitals, Geneva, Switzerland \\ ${ }^{4}$ Medical Diagnostic Discovery Department, BioMérieux, Grenoble, France \\ ${ }^{5}$ Data and Knowledge Laboratory, BioMérieux, Marcy l'Etoile, France \\ ${ }^{6}$ Research and Development Microbiology, BioMérieux, La Balme-les-Grottes, France \\ ${ }^{7}$ Laboratory of Intensive Care, Department of Anaesthesiology, Pharmacology and Intensive Care, Geneva University Hospitals, Geneva, Switzerland
}

\section{Edited by:}

Egija Zaura, Academic Centre for

Dentistry Amsterdam, Netherlands

Reviewed by:

Susan M. Huse, Brown University, USA

Bernd W. Brandt, Academic Centre for Dentistry Amsterdam,

Netherlands

*Correspondence:

Vladimir Lazarevic, Genomic

Research Laboratory, Division of

Infectious Diseases, Geneva

University Hospitals, Rue

Gabrielle-Perret-Gentil 4 ,

1211 Geneva, Switzerland

e-mail:vladimir.lazarevic@

genomic.ch
The spread of microorganisms in hospitals is an important public health threat, and yet few studies have assessed how human microbial communities (microbiota) evolve in the hospital setting. Studies conducted so far have mainly focused on a limited number of bacterial species, mostly pathogenic ones and primarily during outbreaks. We explored the bacterial community diversity of the microbiota from oral and respiratory samples of intubated patients hospitalized in the intensive care unit and we discuss the technical challenges that may arise while using culture-independent approaches to study these types of samples.

Keywords: endotracheal aspirate, supraglottic secretions, microbiota, 16S rDNA profiling, bacterial communities

\section{SUBJECTS AND SAMPLE TYPES}

Supraglottic secretions (SGS) and endotracheal aspirates (ETA) were collected on a daily basis from five subjects over a 4-day period following intubation (Supplementary Material). For each subject, we also included a sample on day $5-11$ depending on availability. None of the patients developed ventilator-associated pneumonia (VAP), so their oral/respiratory bacterial communities likely represent "healthy" microbiota of mechanically ventilated patients.

\section{SEOUENCE DATA PROCESSING}

After pyrosequencing of 16S rDNA V1-3 amplicon libraries from the reverse primer (Supplementary Material), a total of 383,302 sequence reads had an exact match to the barcode sequence. Removal of sequence reads based on (1) the match to the $16 \mathrm{~S}$ rDNA sequence of the reverse primer, (2) length, (3) quality score, (4) the presence of homopolymer runs and (5) ambiguous bases, resulted in 375,612 (98\%), 375,210 (99.8\%), 266,338 (69.5\%), 266,338 (69.5\%), and 264,358 (69\%) sequences, respectively. The BLASTN-based OTU picking, performed as described previously (Lazarevic et al., 2013a) using the Greengenes taxonomy (McDonald et al., 2012), further reduced the dataset to 217,531 sequences (56.8\%) of which 209,477 derived from the 50 clinical (25 SGS and 25 ETA) samples and 8054 sequence reads corresponded to 8 negative controls (reagents). After removal of possibly contaminant $16 \mathrm{~S}$ rDNA sequences (see below) the sample dataset was represented by 194,322 sequences. The number of sequences per sample varied between 9 and 7665 (average 3886, median 4500). The average number of sequences per individual were 24,712 (median 22,763) and 14,153 (median 15,082) for SGS and ETA, respectively.

\section{MICROBIOTA PROFILES}

The phyla Firmicutes, Proteobacteria, Bacteroidetes, Fusobacteria, Tenericutes and Actinobacteria were highly prevalent (42-50 positive samples) and corresponded on average to $>97 \%$ of the $16 \mathrm{~S}$ rDNA sequences in both SGS and ETA samples datasets. The less abundant phyla Spirochaetes, TM7 and Synergistetes were also identified in both samples types (24-30 positive samples). Other phyla, SR1, Cyanobacteria, Thermi and WPS-2 were found each in less than 5 samples at low proportion $(<0.2 \%)$. A total of 115 genera were identified in the dataset. At the genus level, SGS and ETA microbiota showed high similarity in terms of the prevalence (Pearson $R=0.884$ ) and average relative abundance (Pearson $R=0.854$ ). Genera Streptococcus, Neisseria, and Prevotella had the highest proportion in both 
samples types and represented together 56 and $57 \%$ of sequence reads in SGS and ETA, respectively. In contrast, Mycobacterium, the fourth most abundant genus in SGS (6.7\%) and ETA (3.1\%) has been identified in saliva at very low levels (Lazarevic et al., 2011). Interestingly, in a study which included intubated patients, the genus Mycoplasma was found in bronchoalveolar lavages but only in individuals who developed VAP or community associated pneumonia (Bousbia et al., 2012). The other genus from the phylum Tenericutes, Ureaplasma, was frequently identified as dominant organism in tracheal aspirates from mechanically ventilated preterm infants (Mourani et al., 2011).

We compared the SGS and ETA microbiota with those from other body sites available from published studies. Both SGS and ETA bacterial communities determined in our study clustered together with salivary (Zaura et al., 2009; Lazarevic et al., 2010, 2013b; Segata et al., 2012; Ling et al., 2013) and throat (back wall of oropharynx) microbiota (Segata et al., 2012), and were clearly distinct from the skin microbiota (Ling et al., 2013) (unpublished, MG-RAST ID 6526), nasopharyngeal microbiota (Bogaert et al., 2011; Ling et al., 2013) and gut microbiota (Claesson et al., 2009; Segata et al., 2012; Krych et al., 2013; Ling et al., 2013) (Figure 1). This significantly supports the validity of our experimental approach and shows that differences between anatomical sites outweighed the methodological differences related to DNA extraction, PCR amplification and bioinformatics analysis. Our result is consistent with the recent metagenomic studies indicating that the lower respiratory tract microbiota (including trachea) originate mainly from the oral and upper respiratory tract (including oropharynx) in healthy subjects and in disease (Charlson et al., 2011; Cabrera-Rubio et al., 2012; Segata et al., 2012). Similarly, culture-based studies showed that bacterial communities of the pharyngeal and tracheal secretions are similar (Pirracchio et al., 2009).

\section{TECHNICAL CHALLENGES}

Since many bacteria are not readily cultivable, the studies of bacterial communities using culture-independent methods provide a benefit over the traditional approaches in which bacterial identification requires growth under laboratory conditions. However, culture-free molecular methods introduce biases related to: DNA extraction procedure, PCR amplification, sequencing platform used, and bio-informatic analysis (Lazarevic et al., 2013a; Lozupone et al., 2013). Below we discuss some of the challenges in the culture-independent analysis of SGS and ETA related to the physical and microbiological nature of these samples.

\section{VISCOSITY OF SAMPLES}

Because of the high viscosity observed in about $5 \%$ of ETA samples, we added dithiothreitol (DTT) in the lysis buffer for DNA extraction. By dissolving mucus, DTT treatment liquefies samples (Olsson et al., 1993) and allows for further and optimized sample processing in a semi-automated workflow. DTT and other thiolreducing agents used to reduce in vitro viscosity of the mucin (Sheffner, 1963) have the potential to inhibit the subsequent PCR amplification (Deneer and Knight, 1994). We performed DNA extraction with or without DTT addition for six ETA samples and we found that $16 \mathrm{~S}$ rDNA amplicon yields were higher when the

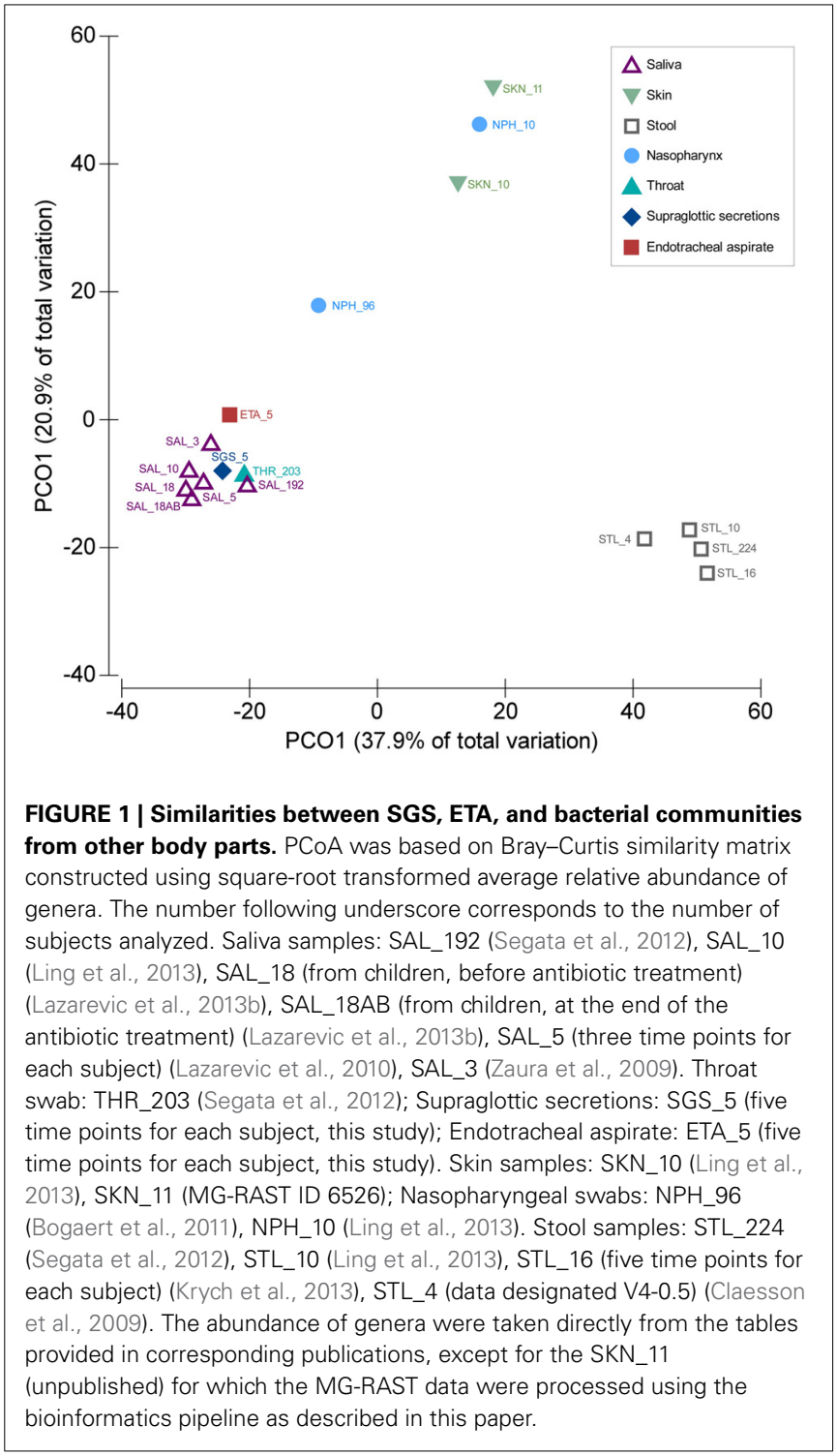

extraction procedure included DTT-treatment (not presented). Therefore, DTT may be systematically added to viscous samples provided that it is efficiently washed away before the PCR step, as evidenced in these conditions.

\section{CO-EXTRACTION OF BACTERIAL AND HUMAN DNA}

Real-time PCR revealed that the bacterial DNA concentration in extracts varied from 0.1 to $4723 \mathrm{pg} / \mu \mathrm{L}$ with median values of 96.2 and $2.3 \mathrm{pg} / \mu \mathrm{L}$ for SGS and ETA, respectively. The yield of human DNA was generally much higher (median $10.1 \mathrm{ng} / \mathrm{uL}$ ) and showed less variation in concentration (Figure 2A). Grice et al. (2008) showed that a mixture of human and bacterial DNA in up to a $100,000: 1$ mass ratio (100:1 cell ratio) did not significantly alter $16 \mathrm{~S}$ rDNA amplification. However, the presence of human DNA is more critical when a whole genome shotgun sequencing approach is to be used to study microbial communities because many reads will derive from host DNA. To circumvent this potential limitation, a method for selective enrichment of microbial 


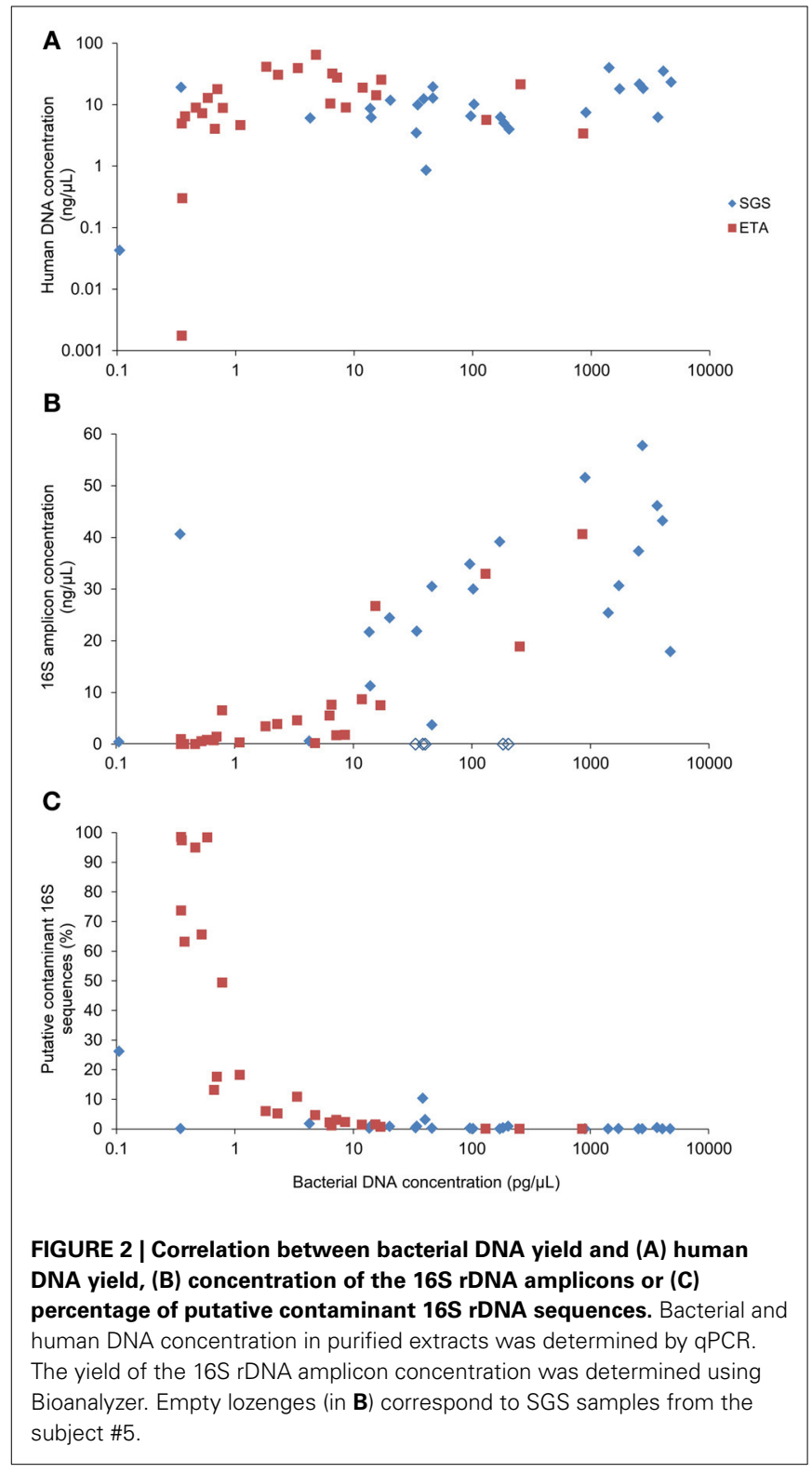

DNA from contaminating human host DNA has been developed (Feehery et al., 2013), but further progress is needed in this area. Alternatively, host DNA sequences may be recognized and removed by bio-informatic analysis (Schmieder and Edwards, 2011).

\section{PCR INHIBITION}

We observed that all of the five SGS samples from one patient (\#5) presumably contained PCR inhibitors. Figure 2B shows that non-diluted SGS samples from this subject did not produce measurable amounts of PCR products. A 100-fold sample dilution was required to obtain a visible band of the 16S rDNA V1-3 amplicon upon electrophoresis. However, sample dilution may not be optimal in cases where the bacterial concentration is low, as it may reduce already low input DNA. The qPCR analysis of the samples from patient \#5 performed after serial dilution did not reveal the inhibitory effect (not presented). This is in line with evidence that PCR inhibition depends on amplification conditions and the DNA polymerase being used (Al-Soud and Rådström, 1998). Therefore, to reduce PCR inhibition, it may be helpful to use genetically engineered DNA polymerases highly tolerant to inhibition (Kermekchiev et al., 2009).

\section{CONTAMINANT DNA}

Reagents used for DNA extraction and PCR may contain bacterial DNA which is overruled by DNA from high-density samples. However, sequence reads derived from samples with low DNA concentration may largely originate from exogenous DNA contamination.

We included in the pyrosequencing run the PCR amplification products obtained using eight negative controls. Any operational taxonomic unit (OTU) that had greater average relative abundance in negative controls than in clinical samples was considered as contaminant. The proportion of putative contaminant $16 \mathrm{~S}$ rDNA sequences was inversely correlated with bacterial DNA concentration in DNA extracts (Spearman $r=-0.850$ ) (Figure 2C). Most contaminating OTUs (93/127) were assigned to Proteobacteria, already identified before as common reagent contaminants (Tanner et al., 1998; Biesbroek et al., 2012; Willner et al., 2012). The sequence reads assigned to the putative contaminating OTUs represented $7.2 \%$ of the reads in the sample dataset. Processing of the sequence datasets using a minimum identity threshold of $99 \%$ and the reference OTU database pre-clustered at $99 \%$ resulted in only slightly higher proportion $(8 \%)$ of putative contaminating sequences. However, distinction between putative contaminants and "true" sequences will remain an important variable in metagenomic approaches.

\section{LOW DNA YIELD}

It remains unclear whether prophylactic chlorhexidine oral rinse, given to all patients in our study, decreases total bacterial load in the trachea as it has been the case with saliva (Veksler et al., 1991). 16S rDNA amplicon libraries deriving from the samples with very low bacterial load resulted in a low number of sequence reads. DNA extraction using larger sample volume (if available) and/or concentration of bacteria by centrifugation may provide a solution. Performing additional PCR cycles in order to increase the amplicon yield has been shown to introduce amplification biases in salivary samples (Lazarevic et al., 2012). Another strategy to cope with low DNA concentration is the use of multiple displacement amplification (MDA) prior to 16S rDNA amplification (Pragman et al., 2012), but MDA may also introduce a representational bias (Marine et al., 2014).

\section{OUTLOOK}

In this pilot study, involving a small number of intubated patients, we pointed to some common issues that may arise when analysing their oropharyngeal and respiratory-tract microbiota. We provided a preliminary characterization of the microbiota associated with these specific sample types that have been only 
weakly (ETA) or not at all (SGS) studied so far using cultureindependent methods. The analysis of larger cohorts of intubated patients with a longer follow-up period may allow to (1) answer whether the oropharyngeal and respiratory microbiota from different patients converge to one or several distinct states during hospitalization and to (2) link microbiome structure to the development of VAP which occurs in up to $30 \%$ of patients receiving mechanical ventilation (Morrow et al., 2010).

\section{ACKNOWLEDGMENTS}

We are grateful to Valérie Nocquet-Boyer for collecting samples.

\section{SUPPLEMENTARY MATERIAL}

The Supplementary Material for this article can be found online at: http://www.frontiersin.org/journal/10.3389/fcimb.2014. 00065/abstract

\section{REFERENCES}

Al-Soud, A. W., and Rådström, P. (1998). Capacity of nine thermostable DNA polymerases To mediate DNA amplification in the presence of PCR-inhibiting samples. Appl. Environ. Microbiol. 64, 3748-3753.

Biesbroek, G., Sanders, E. A., Roeselers, G., Wang, X., Caspers, M. P., Trzcinski, K., et al. (2012). Deep sequencing analyses of low density microbial communities: working at the boundary of accurate microbiota detection. PLoS ONE 7:e32942. doi: 10.1371/journal.pone.0032942

Bogaert, D., Keijser, B., Huse, S., Rossen, J., Veenhoven, R., van Gils, E., et al. (2011). Variability and diversity of nasopharyngeal microbiota in children: a metagenomic analysis. PLOS ONE 6:e17035. doi: 10.1371/journal.pone. 0017035

Bousbia, S., Papazian, L., Saux, P., Forel, J. M., Auffray, J. P., Martin, C., et al. (2012). Repertoire of intensive care unit pneumonia microbiota. PLoS ONE 7:e32486. doi: 10.1371/journal.pone.0032486

Cabrera-Rubio, R., Garcia-Nunez, M., Seto, L., Anto, J. M., Moya, A., Monso, E., et al. (2012). Microbiome diversity in the bronchial tracts of patients with chronic obstructive pulmonary disease. J. Clin. Microbiol. 50, 3562-3568. doi: 10.1128/JCM.00767-12

Charlson, E. S., Bittinger, K., Haas, A. R., Fitzgerald, A. S., Frank, I., Yadav, A., et al. (2011). Topographical continuity of bacterial populations in the healthy human respiratory tract. Am. J. Res. Crit. Care Med. 184, 957-963. doi: 10.1164/rccm.201104-0655OC

Claesson, M. J., O'Sullivan, O., Wang, Q., Nikkila, J., Marchesi, J. R., Smidt, H., et al. (2009). Comparative analysis of pyrosequencing and a phylogenetic microarray for exploring microbial community structures in the human distal intestine. PLoS ONE 4:e6669. doi: 10.1371/journal.pone.00 06669

Deneer, H. G., and Knight, I. (1994). Inhibition of the polymerase chain reaction by mucolytic agents. Clin. Chem. 40, 171-172.

Feehery, G. R., Yigit, E., Oyola, S. O., Langhorst, B. W., Schmidt, V. T., Stewart, F. J., et al. (2013). A method for selectively enriching microbial DNA from contaminating vertebrate host DNA. PLoS ONE 8:e76096. doi: 10.1371/journal.pone.0076096

Grice, E. A., Kong, H. H., Renaud, G., Young, A. C., Bouffard, G. G., Blakesley, R. W., et al. (2008). A diversity profile of the human skin microbiota. Genome Res. 18, 1043-1050. doi: 10.1101/gr.075549.107

Kermekchiev, M. B., Kirilova, L. I., Vail, E. E., and Barnes, W. M. (2009). Mutants of Taq DNA polymerase resistant to PCR inhibitors allow DNA amplification from whole blood and crude soil samples. Nucleic Acids Res. 37, e40. doi: 10.1093/nar/gkn1055

Krych, L., Hansen, C. H., Hansen, A. K., van den Berg, F. W., and Nielsen, D. S. (2013). Quantitatively different, yet qualitatively alike: a metaanalysis of the mouse core gut microbiome with a view towards the human gut microbiome. PLoS ONE 8:e62578. doi: 10.1371/journal.pone. 0062578
Lazarevic, V., Gaia, N., Girard, M., Francois, P., and Schrenzel, J. (2013a). Comparison of DNA extraction methods in analysis of salivary bacterial communities. PLoS ONE 8:e67699. doi: 10.1371/journal.pone. 0067699

Lazarevic, V., Manzano, S., Gaia, N., Girard, M., Whiteson, K., Hibbs, J., et al. (2013b). Effects of amoxicillin treatment on the salivary microbiota in children with acute otitis media. Clin. Microbiol. Infect. 19, E335-E342. doi: 10.1111/1469-0691.12213

Lazarevic, V., Whiteson, K., François, P., and Schrenzel, J. (2011). The salivary microbiome assessed by a high-throughput and culture-independent approach. J. Integr. Omics 1, 25-35. doi: 10.5584/jiomics.v1i1.43

Lazarevic, V., Whiteson, K., Gaia, N., Gizard, Y., Hernandez, D., Farinelli, L., et al. (2012). Analysis of the salivary microbiome using culture-independent techniques. J. Clin. Bioinforma 2, 4. doi: 10.1186/2043-9113-2-4

Lazarevic, V., Whiteson, K., Hernandez, D., François, P., and Schrenzel, J. (2010). Study of inter- and intra-individual variations in the salivary microbiota. BMC Genomics 11:523. doi: 10.1186/1471-2164-11-523

Ling, Z., Liu, X., Luo, Y., Yuan, L., Nelson, K. E., Wang, Y., et al. (2013). Pyrosequencing analysis of the human microbiota of healthy Chinese undergraduates. BMC Genomics 14:390. doi: 10.1186/1471-2164-14-390

Lozupone, C. A., Stombaugh, J., Gonzalez, A., Ackermann, G., Wendel, D., Vazquez-Baeza, Y., et al. (2013). Meta-analyses of studies of the human microbiota. Genome Res. 23, 1704-1714. doi: 10.1101/gr.1518 03.112

Marine, R., McCarren, C., Vorrasane, V., Nasko, D., Crowgey, E., Polson, S. W., et al. (2014). Caught in the middle with multiple displacement amplification: the myth of pooling for avoiding multiple displacement amplification bias in a metagenome. Microbiome 2, 3. doi: 10.1186/2049-2618-2-3

McDonald, D., Price, M. N., Goodrich, J., Nawrocki, E. P., Desantis, T. Z., Probst, A., et al. (2012). An improved Greengenes taxonomy with explicit ranks for ecological and evolutionary analyses of bacteria and archaea. ISME J. 6, 610-618. doi: 10.1038/ismej.2011.139

Morrow, L. E., Kollef, M. H., and Casale, T. B. (2010). Probiotic prophylaxis of ventilator-associated pneumonia: a blinded, randomized, controlled trial. Am. J. Res. Crit. Care Med. 182, 1058-1064. doi: 10.1164/rccm.200912$1853 \mathrm{OC}$

Mourani, P. M., Harris, J. K., Sontag, M. K., Robertson, C. E., and Abman, S. H. (2011). Molecular identification of bacteria in tracheal aspirate fluid from mechanically ventilated preterm infants. PLOS ONE 6:e25959. doi: 10.1371/journal.pone.0025959

Olsson, M., Elvin, K., Lofdahl, S., and Linder, E. (1993). Detection of Pneumocystis carinii DNA in sputum and bronchoalveolar lavage samples by polymerase chain reaction. J. Clin. Microbiol. 31, 221-226.

Pirracchio, R., Mateo, J., Raskine, L., Rigon, M. R., Lukaszewicz, A. C., Mebazaa, A., et al. (2009). Can bacteriological upper airway samples obtained at intensive care unit admission guide empiric antibiotherapy for ventilator-associated pneumonia? Crit. Care Med. 37, 2559-2563. doi: 10.1097/CCM.0b013e3181a57b48

Pragman, A. A., Kim, H. B., Reilly, C. S., Wendt, C., and Isaacson, R. E. (2012). The lung microbiome in moderate and severe chronic obstructive pulmonary disease. PLOS ONE 7:e47305. doi: 10.1371/journal.pone. 0047305

Schmieder, R., and Edwards, R. (2011). Fast identification and removal of sequence contamination from genomic and metagenomic datasets. PLOS ONE 6:e17288. doi: 10.1371/journal.pone.0017288

Segata, N., Haake, S. K., Mannon, P., Lemon, K. P., Waldron, L., Gevers, D., et al. (2012). Composition of the adult digestive tract bacterial microbiome based on seven mouth surfaces, tonsils, throat and stool samples. Genome Biol. 13, R42. doi: 10.1186/gb-2012-13-6-r42

Sheffner, A. L. (1963). The reduction in vitro in viscosity of mucoprotein solutions by a new mucolytic agent, N-acetyl-L-cysteine. Ann. N.Y. Acad. Sci. 106, 298-310. doi: 10.1111/j.1749-6632.1963.tb16647.x

Tanner, M. A., Goebel, B. M., Dojka, M. A., and Pace, N. R. (1998). Specific ribosomal DNA sequences from diverse environmental settings correlate with experimental contaminants. Appl. Environ. Microbiol. 64, 3110-3113.

Veksler, A. E., Kayrouz, G. A., and Newman, M. G. (1991). Reduction of salivary bacteria by pre-procedural rinses with chlorhexidine $0.12 \%$. J. Periodontol. 62 , 649-651. doi: 10.1902/jop.1991.62.11.649 
Willner, D., Daly, J., Whiley, D., Grimwood, K., Wainwright, C. E., and Hugenholtz, P. (2012). Comparison of DNA extraction methods for microbial community profiling with an application to pediatric bronchoalveolar lavage samples. PLoS ONE 7:e34605. doi: 10.1371/journal.pone. 0034605

Zaura, E., Keijser, B. J., Huse, S. M., and Crielaard, W. (2009). Defining the healthy core microbiome of oral microbial communities. BMC Microbiol. 9:259. doi: $10.1186 / 1471-2180-9-259$

Conflict of Interest Statement: This investigation-driven study was financially supported by BioMérieux. The four authors are employees of BioMérieux, a company creating and developing infectious disease diagnostics. The authors declare that the research was conducted in the absence of any commercial or financial relationships that could be construed as a potential conflict of interest.
Received: 17 February 2014; accepted: 06 May 2014; published online: 23 May 2014. Citation: Lazarevic V, Gaïa N, Emonet S, Girard M, Renzi G, Despres L, Wozniak H, Yugueros Marcos J, Veyrieras J-B, Chatellier S, van Belkum A, Pugin J and Schrenzel $J$ (2014) Challenges in the culture-independent analysis of oral and respiratory samples from intubated patients. Front. Cell. Infect. Microbiol. 4:65. doi: 10.3389/fcimb. 2014.00065

This article was submitted to the journal Frontiers in Cellular and Infection Microbiology.

Copyright (c) 2014 Lazarevic, Gaïa, Emonet, Girard, Renzi, Despres, Wozniak, Yugueros Marcos, Veyrieras, Chatellier, van Belkum, Pugin and Schrenzel. This is an open-access article distributed under the terms of the Creative Commons Attribution License (CC BY). The use, distribution or reproduction in other forums is permitted, provided the original author(s) or licensor are credited and that the original publication in this journal is cited, in accordance with accepted academic practice. No use, distribution or reproduction is permitted which does not comply with these terms. 